\title{
Composites Similarity Analysis Method Based on Knowledge Set in Composites Quality Control
}

\author{
Haifeng LI ${ }^{\mathrm{a}}$ \\ Dalian Jiaotong University, DJTU, Dalian, China
}

\begin{abstract}
Composites similarity analysis is an important link of composites review, it can not only to declare composites review rechecking, still help composites applicants promptly have the research content relevant progress and avoid duplication. This paper mainly studies the composites similarity model in composites review. With the actual experience of composites management, based on the author's knowledge set theory, paper analyzes deeply knowledge set representation of composites knowledge, improves the similarity calculation of composites knowledge, and builds the composites similarity level model.
\end{abstract}

\section{Introduction}

In the actual composites quality control, we comprehensive understanding of the whole process of composites audit and then start thinking in practice about the existing problems about current composites audit. Which, in composites auditing, mostly is simply to declare application composites, and no form to analyze application composites, therefore, appeared on a particular research by the repetitive content, not only waste the money, also waste a great deal of resources.

Therefore, how to explore the research content repetitive composites can improve the effectiveness of the research. In the composites audit need to declare in similarity calculation between application composites and the previous composites, sure the similar degree between application composites and previous composites to judge whether the research content of application composites already improved, this is the deep analysis to the composites audit, need the support of the corresponding algorithms.

\section{Knowledge Set Theory}

Knowledge set theory is brought out by the author based on the extension theory and the analysis of the characteristics of knowledge, which is a kind of effective knowledge representation method.

\subsection{Knowledge Set Related Concepts}

Knowledge set (KS) is a collection of knowledge on knowledge carrier, said as the research object of knowledge construction unit. [2]
Various types of knowledge (scientific knowledge, experience knowledge, process knowledge) exist in different types of knowledge carrier (material, person, process). For a project management department, its knowledge system is the sum of this knowledge contained in these knowledge carriers. If take these knowledge in each carrier knowledge sets for a look, then, a knowledge system in project management $=\left\{\mathrm{KS}_{1}, \mathrm{KS}_{2}, \ldots, \mathrm{KS}_{\mathrm{n}}\right\}$. So the whole knowledge system can be described by a knowledge structure constituted by the relationship between knowledge sets.

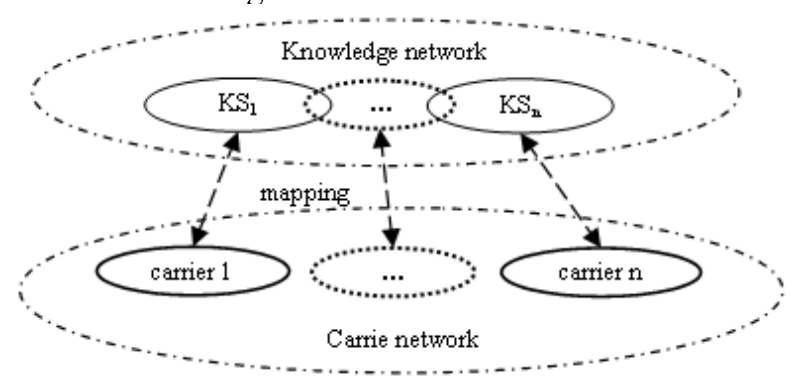

Fig. 1 The Mapped between Knowledge Set and Knowledge Carriers

\section{Extension Representation of Knowledge.}

\subsection{Representation of Knowledge Itself.}

With orderly triad $\mathrm{KS}=(\mathrm{N}, \mathrm{C}, \mathrm{V})$ to represent knowledge set, N, C, V three called three elements of knowledge set, including $\mathrm{KS}, \mathrm{N}$ is knowledge carrier, $\mathrm{C}$ is carrier feature set $\left\{\mathrm{c}_{1}, \mathrm{c}_{2}, \ldots, \mathrm{c}_{\mathrm{n}}\right\}, \mathrm{V}$ is quantum set of $\mathrm{N}$ about $\mathrm{C}\left\{\mathrm{v}_{1}, \mathrm{v}_{2}, \ldots, \mathrm{v}_{\mathrm{n}}\right\} . \mathrm{C}$ and $\mathrm{V}$ constitute

\footnotetext{
${ }^{a}$ Corresponding author: lihaifeng@djtu.edu.cn
} 
binary group $(\mathrm{C}, \mathrm{V})$ called carrier $\mathrm{N}$ characteristics yuan, scope of about features $c_{i}$ written for $V\left(c_{i}\right)$, known as the amount of $c_{i}$ domain.

Therefore, can define knowledge set as

$$
K S=(\mathrm{N}, \mathrm{C}, \mathrm{V})=\left[\begin{array}{ccc}
\mathrm{N}, & c_{1}, & v_{1} \\
& c_{2}, & v_{2} \\
& c_{3}, & v_{3} \\
\ldots & \ldots \\
& c_{n}, & v_{n}
\end{array}\right] .
$$

\subsection{Representation of Knowledge Process}

With orderly triad $\mathrm{T}=(\mathrm{D}, \mathrm{H}, \mathrm{U})$ to represent knowledge process, $\mathrm{D}$ is a verb, which means the way of knowledge transformation; $\mathrm{H}$ represents the characteristics of verbs, such as the object, object, time, place, degree, method, tool, etc. $U$ is the value of D. So, the process of knowledge transformation can be expressed as:

$$
T=(\mathrm{D}, \mathrm{H}, \mathrm{U})=\left[\begin{array}{ccc}
D, & h_{1}, & u_{1} \\
& h_{2}, & u_{2} \\
& h_{3}, & u_{3} \\
\ldots & \ldots \\
& h_{n}, & u_{n}
\end{array}\right] .
$$

\subsection{Representation of Knowledge Relations}

With orderly triad $\mathrm{R}=(\mathrm{S}, \mathrm{A}, \mathrm{Z})$ to represent knowledge relations, where $S$ represents the type of relationship, and A represents the relationship characteristics, Z represents the value of S on A. Well, the relationship between the knowledge sets can be expressed as:

$$
R=(\mathrm{S}, \mathrm{A}, \mathrm{Z})=\left[\begin{array}{ccc}
S, & a_{1}, & z_{1} \\
& a_{2}, & z_{2} \\
& a_{3}, & z_{3} \\
\ldots & \ldots \\
& a_{n}, & z_{n}
\end{array}\right] .
$$

\subsection{Knowledge Set Correlation Analysis Method.}

Use symbols $\sim$ to represent knowledge set correlation. If $\mathrm{KS}_{1}$ and $\mathrm{KS}_{2}$ related, can remember for: $\mathrm{KS}_{1} \sim \mathrm{KS}_{2}$. Concrete research, $\mathrm{KS}_{1}=\left(\mathrm{N}_{1}, \mathrm{c}_{1}, \mathrm{c}_{1}\left(\mathrm{~N}_{1}\right)\right)$, $\mathrm{KS}_{2}=\left(\mathrm{N}_{2}, \mathrm{c}_{2}, \mathrm{c}_{2}\left(\mathrm{~N}_{2}\right)\right)$, if $\mathrm{c}_{1}\left(\mathrm{~N}_{1}\right)=\mathrm{f}\left(\mathrm{c}_{2}\left(\mathrm{~N}_{2}\right)\right)$, including $\mathrm{f}(\mathrm{x})$ for correlation functions, says $\mathrm{KS}_{1}$ and $\mathrm{KS}_{2}$ about features $\left(c_{1}, c_{2}\right)$ is related, remember $\mathrm{c}_{1} \mathrm{KS}_{1} \sim \mathrm{f}\left(\mathrm{c}_{2}\right) \mathrm{KS}_{2}$.

If $\mathrm{KS}_{1}$ and $\mathrm{KS}_{2}$ about certain characteristics with $\left(\mathrm{C}_{1}, \mathrm{C}_{2}\right)=\left\{\left(\mathrm{c}_{11}, \mathrm{c}_{21}\right),\left(\mathrm{c}_{12}, \mathrm{c}_{22}\right), \ldots,\left(\mathrm{c}_{1 \mathrm{n}}, \mathrm{c}_{2 \mathrm{n}}\right)\right\}$ related, namely as $\mathrm{c}_{1 \mathrm{i}}\left(\mathrm{N}_{1}\right)=\mathrm{f}_{\mathrm{i}}\left(\mathrm{c}_{2 \mathrm{i}}\left(\mathrm{N}_{2}\right)\right)(\mathrm{i}=1,2, \ldots, \mathrm{n})$, including $\mathrm{F}(\mathrm{x})=\left\{\mathrm{f}_{1}(\mathrm{x}), \mathrm{f}_{2}(\mathrm{x}), \ldots, \mathrm{f}_{\mathrm{n}}(\mathrm{x})\right\}$ for function sets, then the relationship of $\mathrm{KS}_{1}$ and $\mathrm{KS}_{2}$ can be expressed as

$$
C_{1} K S_{1} \sim F\left(C_{2}\right) K S_{2}=\left[\begin{array}{c}
c_{11} \\
c_{12} \\
\ldots \\
c_{1 n}
\end{array}\right] K S_{1} \sim\left[\begin{array}{c}
\mathrm{f}_{1}\left(c_{21}\right) \\
\mathrm{f}_{2}\left(c_{22}\right) \\
\ldots \\
\mathrm{f}_{n}\left(c_{2 n}\right)
\end{array}\right] K S_{2}
$$

Set $\mathrm{W}=\left\{\omega_{1}, \omega_{2}, \ldots, \omega_{\mathrm{n}}\right\}$ to the research weight of the corresponding feature $\left\{\left(\mathrm{c}_{11}, \mathrm{c}_{21}\right),\left(\mathrm{c}_{12}, \mathrm{c}_{22}\right), \ldots\right.$, $\left.\left(\mathrm{c}_{1 \mathrm{n}}, \mathrm{c}_{2 \mathrm{n}}\right)\right\}$, then the correlation between $\mathrm{KS}_{1}$ and $\mathrm{KS}_{2}$, namely knowledge set degree can determine for

$$
K s R\left(K S_{1}, K S_{2}\right)=\sum_{i=1}^{n} \mathrm{f}_{i}\left(\omega_{i}\right)
$$

\section{Composites Similarity Analysis Method}

\subsection{Knowledge Set Representation of Composites}

The composites as a knowledge carrier, it contains the knowledge is called composites knowledge, according to knowledge set theory, composites knowledge can be represented as

$$
K S_{P}=\left(N_{P}, C, V\right)=\left[\begin{array}{ccc}
N_{P} & c_{1} & v_{1} \\
& c_{2} & v_{2} \\
& c_{3} & v_{3} \\
& \ldots & \ldots \\
& c_{n} & v_{n}
\end{array}\right],
$$

where $\mathrm{N}_{\mathrm{P}}$ is composites, $\mathrm{C}$ is the composites' feature set $\left\{\mathrm{c}_{1}, \mathrm{c}_{2}, \ldots, \mathrm{c}_{\mathrm{n}}\right\}, \mathrm{V}$ is quantum set of $\mathrm{N}$ about $\mathrm{C}\left\{\mathrm{v}_{1}\right.$, $\left.\mathrm{v}_{2}, \ldots, \mathrm{v}_{\mathrm{n}}\right\}$.

\subsection{Similarity Calculation of Composites Knowledge}

There are two composites $\mathrm{KS}_{\mathrm{P} 1}=\left(\mathrm{N}_{1}, \mathrm{c}, \mathrm{c}\left(\mathrm{N}_{1}\right)\right)$ and $\mathrm{KS}_{\mathrm{P} 2}=\left(\mathrm{N}_{2}, \mathrm{c}, \mathrm{c}\left(\mathrm{N}_{2}\right)\right)$, if $\mathrm{c}\left(\mathrm{N}_{1}\right)=\mathrm{f}\left(\mathrm{c}\left(\mathrm{N}_{2}\right)\right)$, including $\mathrm{f}(\mathrm{x})$ for correlation functions, says $\mathrm{KS}_{\mathrm{P} 1}$ and $\mathrm{KS}_{\mathrm{P} 2}$ is related, remember $\mathrm{KS}_{\mathrm{P} 1} \sim \mathrm{f}(\mathrm{c}) \mathrm{KS}_{\mathrm{P} 2}$; If $\mathrm{KS}_{\mathrm{P} 1}$ and $\mathrm{KS}_{\mathrm{P} 2}$ about certain characteristics with $\mathrm{C}=\left\{\mathrm{c}_{1}, \mathrm{c}_{2}, \ldots, \mathrm{c}_{\mathrm{k}}\right\}$ is related, namely $\mathrm{c}_{\mathrm{i}}\left(\mathrm{N}_{1}\right)=\mathrm{f}_{\mathrm{i}}\left(\mathrm{c}_{\mathrm{i}}\left(\mathrm{N}_{2}\right)\right)(\mathrm{i}=1,2, \ldots, \mathrm{k})$, including $\mathrm{F}(\mathrm{x})=\left\{\mathrm{f}_{1}(\mathrm{x}), \mathrm{f}_{2}(\mathrm{x}), \ldots, \mathrm{f}_{\mathrm{k}}(\mathrm{x})\right\}$ for function sets, hen the relationship of $\mathrm{KS}_{\mathrm{P} 1}$ and $\mathrm{KS}_{\mathrm{P} 2}$ can be expressed as

$$
K S_{P 1} \sim F(C) K S_{P 2}=K S_{P 1} \sim\left[\begin{array}{c}
\mathrm{f}_{1}\left(c_{1}\right) \\
\mathrm{f}_{2}\left(c_{2}\right) \\
\ldots \\
\mathrm{f}_{n}\left(c_{n}\right)
\end{array}\right] K S_{P 2}
$$

Set $W=\left\{\omega_{1}, \omega_{2}, \ldots, \omega_{n}\right\}$ to the research weight of the corresponding feature $\mathrm{C}=\left\{\mathrm{c}_{1}, \mathrm{c}_{2}, \ldots, \mathrm{c}_{\mathrm{k}}\right\}$, then the knowledge set degree between $\mathrm{KS}_{\mathrm{P} 1}$ and $\mathrm{KS}_{\mathrm{P} 2}$ can determine for

$$
K S R\left(K S_{P 1}, K S_{P 2}\right)=\sum_{i=1}^{n} \mathrm{f}_{i}\left(\omega_{i}\right)
$$

\subsection{Composites Similarity Level Model.}

Define composites similarity level 


$$
\left(R_{P P}, G, X\right)=\left[\begin{array}{ccc}
R_{P P} & g_{1} & X_{1} \\
& g_{2} & X_{2} \\
& \ldots & \ldots \\
& g_{n} & X_{n}
\end{array}\right]=\left[\begin{array}{ccc}
R_{P P} & g_{1} & <a_{1}, b_{1}> \\
& g_{2} & <a_{2}, b_{2}> \\
\ldots & \ldots \\
& g_{n} & <a_{n}, b_{n}>
\end{array}\right]
$$

where $\mathrm{R}_{P P}$ is the composites similarity degree, $\mathrm{g}_{\mathrm{i}}(\mathrm{i}=1$, $2, \ldots, n)$ is the ith evaluation grade, Interval $X_{i}$ $=<a_{i}, b_{i}>$ is the energy range of the $R_{P P}$ ith evaluation grade $g_{i}$.

If the similarity with $\mathrm{KS}_{\mathrm{P} 1}$ and $\mathrm{KS}_{\mathrm{P} 2}$ is $\mathrm{R}_{\mathrm{PP}}\left(\mathrm{K}_{\mathrm{P} 1}\right.$, $\left.K_{P 2}\right) \in X_{i}$, then $i$ is the similarity level between $K_{P_{1}}$ and $\mathrm{KS}_{\mathrm{P} 2}$, and according to the correlation degree function of matter-element theory can calculate the membership degree $\mathrm{K}_{\mathrm{i}}\left(\mathrm{R}_{\mathrm{PP}}\left(\mathrm{KS}_{\mathrm{P} 1}, \mathrm{KS}_{\mathrm{P} 2}\right)\right)$ of the similarity level, and can understand more details of $\mathrm{KS}_{\mathrm{P} 1}$ and $\mathrm{KS}_{\mathrm{P} 2}$ similar degree.

\section{Summary}

Composites similarity analysis plays an important role in composites review. Composites similarity analysis not only is the necessary means in composites review, but also can help composites applicants know the situation about declare content in the related research, avoid duplication. Composites similarity analysis also provides methods for future composites integration.

\section{Acknowledgements}

This research was financially supported by the National Natural Science Foundation of China (Grant NO. 71301016), the Social Science Foundation of Liaoning Province (Grant NO. L15BGL002) and the Outstanding Talent Support Program of Liaoning Province (Grant NO. WJQ2015006).

\section{References}

1. X. Xuan and Y. Jiang, "The Thinking of Improving Local Science Operation Mode", Science, vol. 11 (suppl), pp. 66-68, 1997.

2. H. Li, Y. Dang. "Research on Knowledge Connotation and Representation in Science and Technology Composites Management", Composites management technology, vol. 8 (2), pp. 29-34, 2010.

3. W. Cai, "Extension theory and its application", Chinese Science Bulletin, vol. 44(17), pp. 1538-1548, 1999. 